\title{
A Study of the Corrosion Kinetics by Coulometric Detection of Corrosion Products on a Glass Carbon Electrode
}

\author{
A. E. Kuzmak \\ Laboratory of monitoring of anticorrosion materials, A.N.Frumkin Institute of Physical Chemistry and Electrochemistry, \\ Russian Academy of Sciences (IPCE RAS). Moscow 119991, Leninsky prospect 31, Russia \\ *Correspongding Author:kuzmak@ipc.rssi.ru
}

Copyright (c) 2014 Horizon Research Publishing All rights reserved.

\begin{abstract}
The paper reports the theoretical and experimental bases of the CDCP (Coulometric detection of corrosion products) method and examples of its application for the quantitative determination of the ionic forms of corrosion products of carbon steel, including the heat-affected corrosion areas of welding seams under strain ageing (ACWS). The experiment technique that we developed allowed us to perform selective determination of corrosion products (e.g., $\mathrm{Fe}^{+2}$ and $\mathrm{Fe}^{+3}$ in a single experiment) in the range of $1-5 \mu \mathrm{g}$ with standard deviation $\mathrm{s}_{\mathrm{r}}=0.05$.
\end{abstract}

Keywords Coulometric Detection, Corrosion Product, Ionic Form, CDCP, Corrosion Kinetic

\section{Introduction}

Though the results of corrosion are evident, determination of corrosion damage is not a trivial task. In the "electrolyte-oxide-metal" boundary zone, processes governed by various physical laws occur upon change in conductivity type. Consequently, the methods of recording the results of corrosion measurements differ from each other in corrosion estimation criteria and by the parameters determined by these methods.

This forces corrosion scientists to use indirect estimation criteria that rely on various concepts of the form of the result to be obtained, what method should be used to obtain the results, and in what form they should be provided for interpretation [1-3].

In current laboratory practice, the corrosion rate of steel is generally evaluated by polarization and gravimetric methods. A match between the results of both measurement types is either achieved by appropriate calibration or not achieved at all, particularly in the case of prolonged exposures.

In "accelerated" techniques for corrosion testing, mass transfer of charge carriers is stimulated artificially (e.g., by incorporating a specimen of a metal, possibly with a protective coating, as the anode into a direct current circuit). In this situation, a narrow area of the near-surface volume ("reaction space") of the specimen being tested is affected by electric field with an intensity of thousands of $\mathrm{V} / \mathrm{cm}$.

In other words, the technology of present-day polarization methods implies an impact on the specimen during data acquisition. This approach distorts the actual picture of interaction of the object being studied with the corrosive medium and hence results in a mismatch between the results of polarization and mass loss measurements. Thus, the results of measuring the electrical parameters of the state of a system being monitored not always match the conditions of spontaneous corrosion.

As shown in review [4], one of the origins of these differences is that the electrochemical processes that occur within a layer of rust contacting an electrolyte consist of a number of subprocesses involving products of redox reactions, results of mass transfer, migration of electric charges between the interfaces within the layer, etc.

In [5], the corrosion rates of carbon steel exposed for various periods of time were estimated by the polarization method (MPR) and concurrently by the mass loss method. The results have shown that this method frequently gives erroneous values of corrosion parameters. The reason is that even small polarization used in electrochemical studies can make the structure-phase state of iron in the layer of corrosion products $(\beta-\mathrm{FeOOH})$ a participant of the cathodic reaction that can result in an overestimated corrosion rate [6].

Studies of corrosion kinetics by electrochemical impedance spectroscopy (EIS) have shown that the shape of impedance plots is noticeably affected by diffusion processes in the layer and/or pores of rust on a steel electrode which makes it more difficult to obtain valid kinetic data [7].-

It should also be noted that worldwide experience of EIS application [8] for estimation of the protective effect of "solution-metal-coating" systems has revealed the method to have limitations. As we believe, the main limitation is that 
the inherently non-linear "elementary electrochemical cell" is simulated by a linear model of "capacitor with losses". It should be noted that any virtual "capacitor - resistor" pair corresponds to a principally indefinable multitude of real states of an "electrolyte-coating-metal" system. Since electrolyte transfer to the metal surface through a non-metal layer (electrolyte diffusion and interaction with coating components, reactions at the "coating-metal" interface, etc.) is multivariate and non-steady-state and hence "electrical" simulation becomes physically meaningless. As a result, the method in general becomes suitable for integral comparative estimates only [9].

In fact, of the methods widely used for testing the corrosion resistance of metals, only the mass loss (gravimetric) method makes it principally possible to determine the main process parameter, namely the mass loss $(\Delta m)$.

However, though the estimation criterion $\Delta m / \Delta t$ ( $m-$ metal mass; $t$ - specimen exposure time) is quite demonstrative, the mass loss method cannot identify the kinetics of changes in the ionic composition of the corrosion products, e.g., $\mathrm{Fe}^{2+}$ and $\mathrm{Fe}^{3+}$ ions, that play an essential role in the studies of corrosion of steel and alloys or the efficiency of protective systems. Furthermore, the mass loss method nearly does not allow one to estimate objectively the kinetics of corrosion in case of small mass losses, e.g., during the initial period of the corrosion process: under a layer of protective coating, inhibitor, multicomponent alloy, etc.

The use of the advantages of assessing the main corrosion parameter while eliminating the limitations of the mass loss approach allowed us to formulate the following requirements for the measurement criterion [10]:

- quantitative determination of the main corrosion parameter;

- elimination of the effects of the measuring system on the specimen being tested;

- clarity of in situ measurement results;

- accuracy, selectivity, high sensitivity, and efficiency of the measurements.

It is shown in this paper that the Coulometric Detection of Corrosion Product (CDCP) considered below is the optimum method for correct estimation of the corrosion kinetics based on the proposed criterion.

\section{Bases of CDCP Theory and Technology}

The principal advantages of coulometric detection result from the three main features: high-precision determination of ions, selectivity, and no need for reference standards [11].

To date, coulometry was mainly used for high-precision determination of inorganic compounds, uranium and transuranium elements, noble metals, in development of detectors for liquid chromatography, etc.

Notwithstanding the obvious advantages of coulometry, its application in contemporary analytic practice was limited, in particular, because of the lack of new electrode materials and standard measuring instruments. As analysis of research experience over the past decade has shown, the two reasons mentioned above became the main obstacles to the application of coulometry in traditional analysis instead of laborious gravimetrical determinations of the macro content of inorganic compounds [12].

On the other hand, over the past 20 years, the authors of this review working at the A.N.Frumkin Institute of physical chemistry and electrochemistry of the Russian Academy of Sciences obtained new results in the field of metal corrosion kinetics in electrolyte solutions and in the gas-vapor phase. These studies were the first to employ the advantages of the coulometric approach for recording the corrosion kinetics according to the requirements of the measurement criterion.

The method theory is based on Faraday's law [13], according to which the mass $m(\mathrm{~g})$ of a compound obtained in an electrochemical reaction is related to the total electric charge converted during the reaction by the following equation:

$$
m=K_{e} \cdot q
$$

where: $K_{\mathbf{e}}=n \cdot M / F(g / C b)$ is the electrochemical equivalent of the compound or reaction;

$n$ is the number of electrons;

$M$ is the molecular mass of the compound being discharged;

$F$ is the Faraday constant $\left(F=\bar{e} \cdot N_{A}=96485.338 \mathrm{Cb}\right)$;

$\bar{e}$ is the electron charge;

$N_{A}$ is the Avogadro number;

$q(\mathrm{Cb})$ is the total charge of the ions of the compound being determined (here, the corrosion products);

$t$ (seconds) is the elapsed electrolysis time.

However, not the charge amount but current is recorded in today's coulometric experiments, i.e., the charge passed through the measuring cell in a unit of time, i.e., $I(t)=q(t) / t$ (Amperes per second). If we assume that the "instantaneous" current is $I(t)=d q(t) / d t$, then equation (1) can be transformed to:

$$
\mathrm{m}=\mathrm{n} \cdot \mathrm{M} / \mathrm{F} \int \mathrm{I}(\mathrm{t}) \mathrm{dt}
$$

Since the $F$ constant is an analytical standard, coulometric measurements require no chemical standards. Hence, by measuring current $I(t)$ and process time $t$, one can determine with high accuracy the amount of the compound that has undergone electrochemical conversion. If only one electrochemical reaction occurs, its stoichiometry can be quantitatively related to the total electric charge $q$ that passed through the cell in accordance with Faraday's law (1).

In other words, the electrochemical stoichiometry of a particular reaction is in strict compliance of the $q$ value with the amount of the final electrolysis product (Eq. 2) at "current yield"

$$
P=m_{\text {det }} / m_{\text {added }} \approx 1
$$

( $m_{\text {det }}$ and $m_{\text {added }}$ designate the amounts of the compound that were determined and added, respectively). 
Thus, implementation of coulometric measurements is possible provided that three principles are observed:

- the current yield is $100 \%$;

- accuracy and selectivity of charge determination for the ions of the compound being determined;

- reliable determination of the time when the measuring process is completed.

\subsection{Estimation of "current yield" Values}

It is important to note that the informative value of a corrosion experiment becomes particularly high if one can record data for some initial time period of the corrosion process (micro quantities of corrosion product ions). From the coulometric technique point of view, this implies ion discharge currents in the range from $10^{-8}$ to $10^{-6} \mathrm{~A}$.

However, measurements in the micro current range on a glass-carbon indicating electrode (hereinafter referred to as $I E$ ) showed experimentally that there is a quantitative imbalance between the charge $q$ of a certain compound added to the reference solution and its measured amount. Analysis of the results obtained using an $I E$ of another type has shown that at the microlevel, the measured current yield $P$ was also noticeably smaller than $100 \%$, irrespective of the nature of the ions being determined. The "shortage" was usually explained by imperfections of the measuring devices and techniques, faults in the preparation of cells, electrode materials, reference solutions, and even by discovery of new forms of a compound being determined [14-15].

\subsection{Electrolysis kinetic zones}

The discovered "imbalance" is accompanied by the formation of electrolysis kinetic zones possessing individual characteristics (hereinafter, " $\kappa$-zones") that do not obey the classical equation of electrolysis [11].

In other words, the electrolysis process on the $I E$ at the discharge potentials of the compound ions (e.g., $E_{\mathrm{Fe} 3+} \leftrightarrow$ $\left.E_{\mathrm{Fe} 2+}\right)$ occurred within each measuring cycle (cathode $\leftrightarrow$ anode) consecutively in a number of $\kappa$-zones according to the following equation:

$$
I_{i}=I_{0 i} \exp \left(-v_{i} t / I_{b g}\right)
$$

where:

$$
\mathrm{v}_{\mathrm{i}}=\mathrm{I}_{\mathrm{i}} / \mathrm{t}_{\mathrm{i}}
$$

is the electrolysis rate in the $\mathrm{i}$-th $\mathrm{K}$-zone; Ii is the electrolysis current; I0 $\mathrm{i}$ is the initial current; ti is the time window of K-zone existence; Ibg is the background current; $i$ is the sequential number of the K-zone.

As an example, Table 1 lists the electrolysis rates vi and current yields $\mathrm{Pi}$ for five $\kappa$-zones in the $\mathrm{Fe} 2+\rightarrow \mathrm{Fe} 3+$ process.

As one can see from Table 1, each K-zone of electrolysis is characterized by two experimental constants, namely, vi and
Pi that do not depend on the amount of the compound being determined in the i-th K-zone.

Table 1(a). $\quad \mathrm{v}_{\mathrm{i}}$ and $\mathrm{P}_{\mathrm{i}}$ values during $\mathrm{Fe}^{2+} \rightarrow \mathrm{Fe}^{3+}$ discharge on a carbon-glass IE $\left(\mathrm{s}_{\mathrm{r}}=0.05\right)$

\begin{tabular}{|c|c|c|}
\hline $\mathrm{i}$ & $\mathrm{v}_{\mathrm{i}}, \mu \mathrm{A} / \mathrm{s}$ & $\mathrm{P}_{\mathrm{i}}, \%$ \\
\hline 1 & 0.095 & 25 \\
\hline 2 & 0.15 & 33 \\
\hline 3 & 0.22 & 50 \\
\hline 4 & 0.33 & 67 \\
\hline 5 & 0.50 & 100 \\
\hline
\end{tabular}

Studies on the nature of physical phenomena on a glass-carbon surface revealed that changes in potential cause structural reorganization processes. Such processes accompanied by a decrease in the degree of interphase boundary ordering result in excitation of reactive surface states (SS) with relaxation times $\quad \tau_{\mathrm{ss}}<10^{-6} \mathrm{~s}$ [16-17].

The concept of SS' as electronic states of various types in a crystal was introduced in [18-20]. The possibility that SS' associated with adsorbed atoms exist was considered in [21].

Since glass-carbon, which is a semimetal, is converted to a semiconductor in a strong electric field, its zone structure acquires a forbidden gap where additional energy levels can appear that serve as "traps" for ions discharged via the tunneling mechanism [22-23]. The functioning of SS' as potential "traps" is also supported by the lack of chemical processes or adsorption of solution components on the semimetal surface, irrespective of the preliminary treatment of the electrode in the cathodic-anodic cycle [24].

Since the developed methodology of coulometric determination of corrosion products allows accurate and reproducible determination of all changes in vi parameter (4) during electrolysis, it is reasonable to assume that the variability of current yield $\mathrm{Pi}$ in the $\kappa$-zones (in our case, the ratio of the fractions of the charges of $\mathrm{Fe} 2+, 3+$ ions recorded in the measuring circuit to the fraction of trapped ions) can be due to trapping of a fraction of ions by active SS'.

Thus, application of the "K-zone" concept in measurements in the microcurrent range solves the problem of estimating the "true" $\mathrm{P}$ values by taking into account the properties of the electrode surface and enabling an experimental determination of charge $q$ of an electrically converted compound at $\mathrm{P} \approx 1$ according to Faraday's law.

\subsection{Instrumentation}

The following equipment was used in coulometric measurements of the kinetics of corrosion products:

- an IPC-PRO electrochemical interface with specialized control software;

- a glass beaker as the test cell;

- a silver chloride reference electrode;

- carbon fiber as the auxiliary electrode;

- in our experiments, the indicator electrode made of 
SU-2000 glass-carbon played the role of the measuring cell into which the reference electrolyte, the reference electrode, and the auxiliary electrode were placed.

It should be noted that a semimetal was selected as the $I E$ cell material due to its unique properties in comparison with other electrode materials [25]:

- ideal polarization range: $-0.8<p<+0.8 \mathrm{~V}$;

- isotropy of thermal, electrical, and mechanical properties;

- low gas permeability $\left(D<<10^{-12} \mathrm{~cm}^{2} / \mathrm{s}\right)$.

- high sensitivity of the zone structure to external effects (electromagnetic field, admixtures, coordination unsaturated atoms,

structural defects, charged centers, etc.);

- high mobility of the conductivity electrons $(\mu=$ $\left.8000-9200 \mathrm{~cm}^{2} / \mathrm{V} \cdot \mathrm{s}\right)$;

- a specific resistance range $\left(\rho=10^{-4}-10^{8} \mathrm{Ohm} \cdot \mathrm{cm}\right)$.

\subsection{Metrological estimation of the measurement result}

In order to determine how well the measurement results match the actual values and to estimate the reproducibility of coulometric measurements, analysis of standard solutions (containing $\mathrm{Fe}^{3+}$ and $\mathrm{Fe}^{2+}$ ions) is carried out by the "added-found" method (Table 2).

\subsection{Experimental procedure}

Schematically, the experiment involves three main stages:

1. Exposure of the test specimen to a corrosive medium for a specified period of time.
2. Preparation of aliquotes containing ions (corrosion products) for coulometric analysis.

Aliquotes with the ions (corrosion products) are sampled from the corrosive medium or from the metal surface, or obtained by extraction from a coating (inhibitor), and then preserved in order to retain the ionic forms.

3. Coulometric analysis of an aliquote is a process of discharge (electrolysis) of corrosion products (ions) placed into the $I E$.

Coulometric analysis includes: $i$, registration of discharge currents of iron ions $\mathrm{Fe}^{2+} \leftrightarrow \mathrm{Fe}^{3+}$ in the к-zones at discharge potentials $E_{\text {cathode }} \leftrightarrow E_{\text {anode }}$; and $i i$, calculation of the charge $q$ and mass $m$ of corrosion products (ions) by the control software using Equations 2-5.

One can see from Table 2 that the mismatch between the amounts of $\mathrm{Fe}^{2+}$ and $\mathrm{Fe}^{3+}$ is statistically insignificant and the reproducibility of the measurement results is $s_{r}=0.03-0.06$.

It follows from these results that data on the coulometric estimation of $\mathrm{Fe}^{2+}$ and $\mathrm{Fe}^{3+}$ amounts fairly reflect the corrosion process.

As an example, Table 2 gives comparative results of gravimetric and coulometric determination of mass loss $\Delta \mathrm{m}$ on St20 steel in $3 \% \mathrm{NaCl}$ at $p H=5.5$ for 168 and $672 \mathrm{~h}$.

Evidently, the reproducubility of $\Delta m$ determination by CDCP is 5-7 times higher than by the gravimetric method and is at the same level as the reproducubility of the results of analyzing the standard $\mathrm{Fe}^{2+}$ and $\mathrm{Fe}^{3+}$ solutions (Table 1).

Some examples of corrosion determination by CDCP are considered below.

Table1(b). Analysis results for standard $\mathrm{Fe}^{3+}$ and $\mathrm{Fe}^{2+}$ solutions, $\mu \mathrm{g}$ in $3 \% \mathrm{NaCl}, \mathrm{pH}=5.5$, exposure for 168 or $672 \mathrm{~h}(\mathrm{n}=4 ; \mathrm{p}=0.95)$.

\begin{tabular}{|c|c|c|c|c|c|}
\hline $\mathrm{Fe}^{3+}$ added to $\mathrm{Fe}^{2+}$ in 1:1 ratio*) & Found $\mathrm{Fe}^{3+}$ & $\mathrm{Sr}$ & $\mathrm{Fe}^{2+}$ added to $\mathrm{Fe}^{3+}$ in $1: 1$ ratio*) & $\mathrm{Found}^{3+}$ & $\mathrm{Sr}$ \\
\hline 1.5 & $1.48 \pm 0.07$ & 0.05 & 1.5 & $1.6 \pm 0.1$ & 0.06 \\
2.0 & $2.0 \pm 0.1$ & 0.06 & 2.0 & $2.05 \pm 0.08$ & 0.04 \\
3.0 & $3.0 \pm 0.2$ & 0.06 & 3.0 & $3.1 \pm 0.01$ & 0.05 \\
4.5 & $4.4 \pm 0.2$ & 0.05 & 4.5 & $4.6 \pm 0.01$ & 0.03 \\
6.0 & $6.2 \pm 0.2$ & 0.04 & 6.0 & $6.1 \pm 0.2$ & 0.03 \\
\hline
\end{tabular}

*) The measurements carried out at $\mathrm{Fe}^{3+}: \mathrm{Fe}^{2+}$ ratios of $1 / 4$ and $4 / 1$ showed similar metrological results.

Table2. Comparative estimation of $\Delta \mathrm{m}$.

\begin{tabular}{|c|c|c|c|c|c|}
\hline \multirow{2}{*}{ Method } & \multirow{2}{*}{ Ion } & \multicolumn{2}{|c|}{$168 \mathrm{~h}$} & \multicolumn{2}{c|}{$672 \mathrm{~h}$} \\
\cline { 2 - 6 } & & $\Delta \mathrm{m}, g$ & $\mathrm{~s}_{\mathrm{r}}$ & $\Delta \mathrm{m}, g$ & $\mathrm{~s}_{\mathrm{r}}$ \\
\hline \multirow{2}{*}{ Gravimetric } & - & $0.040 \pm 0.002$ & 0.05 & $0.15 \pm 0.02$ & 0.14 \\
\hline \multirow{3}{*}{ Coulometry } & $\mathrm{Fe}^{3+}$ & $0.0127 \pm 0.0001$ & 0.008 & $0.050 \pm 0.002$ & 0.04 \\
\cline { 2 - 6 } & $\mathrm{Fe}^{2+}$ & $0.0092 \pm 0.0003$ & 0.03 & $0.0378 \pm 0.0008$ & 0.02 \\
\cline { 2 - 6 } & $\mathrm{Fe}^{3+}+\mathrm{Fe}^{2+}$ & $0.0219 \pm 0.0002$ & 0.009 & $0.088 \pm 0.002$ & 0.02 \\
\hline
\end{tabular}




\section{Examples of CDCP application}

Figures 1-3 demonstrate the corrosion kinetics $\Delta m(t)$ of St20 steel in $3 \% \mathrm{NaCl}$ solution at $\mathrm{pH} 1.2 ; 5.5$ and 11.1 obtained by CDCP

3.1. Carbon steel corrosion kinetics for $\mathrm{Fe}^{2+}, \mathrm{Fe}^{3+}$, and $\mathrm{Fe}^{2+}+\mathrm{Fe}^{3+}$, and by the gravimetric method for $\mathrm{Fe}^{2+}+\mathrm{Fe}^{3+}$ (- gravimetric method; $\mathrm{Fe}^{3+}+\mathrm{Fe}^{2+} ; \quad \boldsymbol{\Delta} \mathrm{Fe}^{2+} ; \circ \mathrm{Fe}^{3+}$ ).

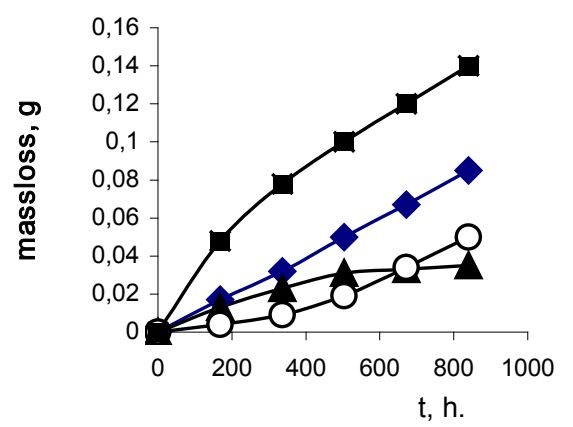

Figure 1. $\mathrm{pH}=1.2$.

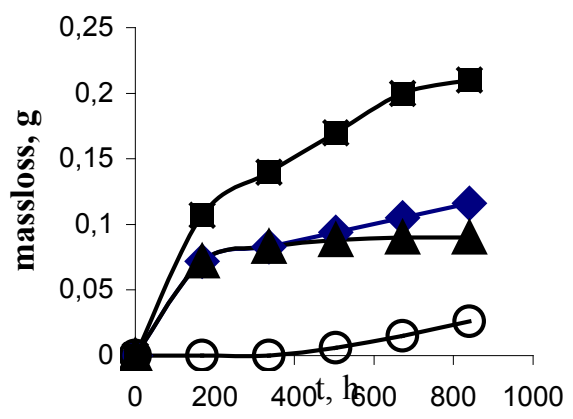

Figure 2. $\mathrm{pH}=5.5$.

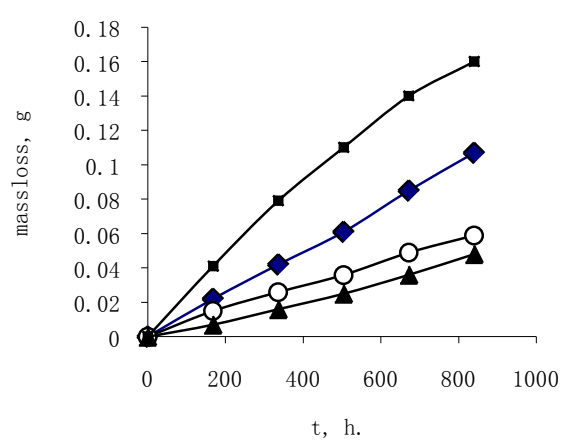

Figure 3. $\mathrm{pH}=11.1$

One can see from the Figures that, according to coulometric measurements of $\mathrm{Fe}^{2+}+\mathrm{Fe}^{3+}$, the rate of release of corrosion products to the corrosive medium acquires a constant value starting from $168 \mathrm{~h}$ of the experiment at all the $\mathrm{pH}$ values. This allows one to forecast the development of the corrosion process with high reliability. Results of mass loss measurements $m(t)$ do not allow such unambiguous conclusions to be made, since errors related to mechanical treatment and etching of blank specimens before the weighing are inevitable.

It is particularly important that the coulometric approach allows one to obtain information about the valence of corrosion products $\left(\mathrm{Fe}^{2+}, \mathrm{Fe}^{3+}\right)$ and about the kinetics of their formation in a corrosive electrolyte. In fact, it is evident from Figs. 1-3 that insoluble $\mathrm{Fe}^{2+}$ oxides are mostly formed on the metal surface at $\mathrm{pH}=1.2$ while $\mathrm{Fe}^{3+}$ oxides are mostly formed at $\mathrm{pH}=11.1$. At $\mathrm{pH}=5.5$, mixed compounds are formed, since the rates of release of $\mathrm{Fe}^{2+}$ and $\mathrm{Fe}^{3+}$ ions into the electrolyte are nearly the same.

\subsection{Corrosion estimation of heat-affected corrosion areas of welding seams under strain ageing.}

It is known [26] that operation of the majority of tube steels faces the problem of stress ageing that accelerates the formation of segregates and impairs the viscoplastic properties. These structural changes also cause spatial deformation of electronic configurations thus forming heterogeneity zones on the metal surface. While the physical mechanisms of stress ageing are known, the relationship between this effect and the corrosion resistance of tube steels has almost not been studied.

The CDCP method was used to study the corrosion kinetics of heat-affected corrosion areas of welding seams on tube steel after stress ageing and tempering.

This example considers the following zones of accumulation of corrosion products, viz., $\mathrm{Fe}^{2+}$ and $\mathrm{Fe}^{3+}$ ions:

- zone $\boldsymbol{I}$ - the surface of a metal support with a layer of corrosion products formed;

- zone $\boldsymbol{I I}$ - the bulk of the corrosive medium in the test cell.

Corrosion products were determined using specimens of $17 \mathrm{GS}$ pipe steel that underwent controlled rolling at a strain extent of $10 \%$ and tempering at $250^{\circ} \mathrm{C} . \quad \mathrm{A} 30 \mathrm{~g} / \mathrm{l} \mathrm{NaCl}$ solution with $\mathrm{pH}=7$ was used as the corrosive medium. The total test time was $3 \mathrm{~h}$. Samples were withdrawn every 0.25 h.

Depending on the cooling rate $W$, the following ACWS variants were tested:

No. 1. $W=3^{\circ} \mathrm{C} / \mathrm{s}$ (ferrite $-40 \%$; bainite $-60 \%$; martensite $-0 \%)$.

No. 2. $W=8^{\circ} \mathrm{C} / \mathrm{s}$ (ferrite $-5 \%$; bainite $-87 \%$; martensite $8 \%)$.

No. 3. $W=50^{\circ} \mathrm{C} / \mathrm{s}$ (ferrite $-0 \%$; bainite - $45 \%$; martensite $-45 \%)$.

Stress ageing of $17 \mathrm{GS}$ steel specimens was carried out in compliance with GOST (Russian State Standard) 7268.

\subsection{Discussion of the Results}

The kinetic plots of the amounts of $\mathrm{Fe}^{2+}$ and $\mathrm{Fe}^{3+}$ ions (corrosion products) in zones $I$ and $I I$ for specimens No. 1 - \$; No. 2 - - ; No. 3 - $\boldsymbol{\Lambda}$ are presented below. Figures 4 and 5 show the time dependences of the total mass $\left(\mathrm{Fe}^{2+}+\mathrm{Fe}^{3+}\right)$ of 
insoluble corrosion products in zones $\boldsymbol{I}$ and $\boldsymbol{I} \boldsymbol{I}$.

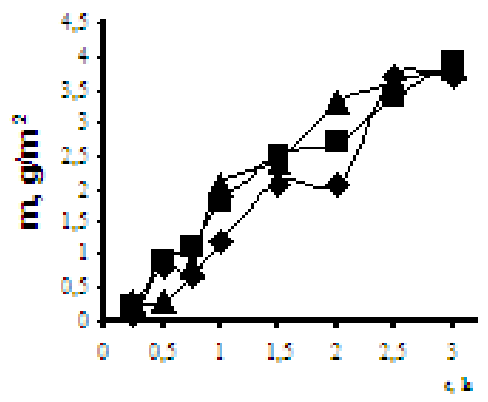

Figure 4

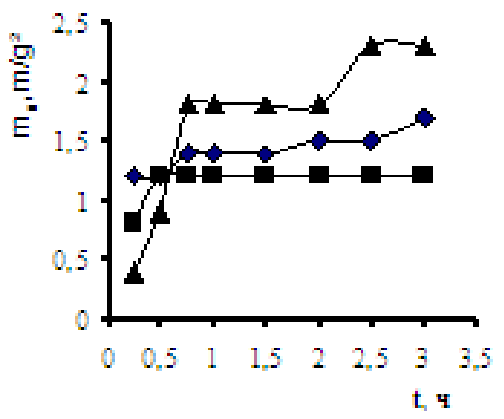

Figure 5

As one can see in Fig. 4, the total amount of ions formed in zone $I$ in $3 \mathrm{~h}$ of exposure is nearly the same at all cooling rates. In fact, the $m_{l}$ values for specimens no. 1 , no. 2 and no. 3 are $3.72 \mathrm{~g} / \mathrm{m}^{2} ; 3.9 \mathrm{~g} / \mathrm{m}^{2}$ and $3.8 \mathrm{~g} / \mathrm{m}^{2}$, respectively. On the other hand, similar values of $m_{I I}$ in zone $\boldsymbol{I I}$ (Fig. 5) are 1.72 $\mathrm{g} / \mathrm{m}^{2} ; 1.2 \mathrm{~g} / \mathrm{m}^{2}$; and $2.3 \mathrm{~g} / \mathrm{m}^{2}$ for specimens no. 1 , no. 2 and no. 3 , respectively. This fact indicates that the formation of oxide layers on the surface of each specimen has certain specific features, while specimen no. 2 has a clear "anti-corrosive" advantage.

In order to study the formation of an oxide structure in the "solution-metal" interphase space more thoroughly, we carried out a coulometric study of the rate of accumulation of $\mathrm{Fe}^{2+}(\bullet)$ and $\mathrm{Fe}^{3+}(0)$ ions in both zones. Figures $6(\mathrm{a}, \mathrm{b}, \mathrm{c})$ and 7 (a,b,c) demonstrate separately the kinetics of accumulation of ion masses $m$ for specimens no. 1, no. 2 and no. 3 in zones $\boldsymbol{I}$ and $\boldsymbol{I I}$ respectively.

In fact, on specimen no. 1 (Fig. 6a) featuring the maximum amount $40 \%$ of ferrite $(60 \%$ - bainite, $0 \%$ martensite) the minimum amount of corrosion products was found after exposure for $0.25 \mathrm{~h}$ in zone $I$ and the maximum amount was found in zone $I I$ in comparison with specimens 2 and 3 (Fig. 7a). It should be noted here that iron preferentially exists as $\mathrm{Fe}^{2+}$ in both zones. Hence it can be assumed that a layer of corrosion products with the smallest thickness and poorl y penetrable for oxygen in comparison with the other specimens was formed in $0.25 \mathrm{~h}$ on the surface of specimen no. 1. The $\mathrm{Fe}^{2+} \rightarrow \mathrm{Fe}^{3+}$ oxidation process was detected in zone $\boldsymbol{I I}$. In this case, the growth in the $\mathrm{Fe}^{3+}$ amount after exposure for $0.25 \mathrm{~h}$ approximately matched the decrease in the $\mathrm{Fe}^{2+}$ amount (Fig. 7a), showing an indication of a "protective effect". detected after $0.25 \mathrm{~h}$ in zone $\boldsymbol{I I}$ (Fig. $7 b)$.

On specimen no. 2 (bainite $87 \%$, ferrite $5 \%$, martensite $8 \%$ ), only $\mathrm{Fe}^{3+}$ ions were. A corrosion product, $\mathrm{Fe}^{2+}$, was detected after $0.25 \mathrm{~h}$ only in zone $\boldsymbol{I I}$ (рис.7b) where its amount increased intensely for $0.75 \mathrm{~h}$. During the same time period, $\mathrm{Fe}^{2+}$ ions appeared in zone $\boldsymbol{I}$ (Fig. 4b) to form a "protective barrier". From this point on, the increase in the amount of $\mathrm{Fe}^{3+}$ in zone $\boldsymbol{I I}$ equals the decrease in $\mathrm{Fe}^{2+}$ amount (6b); this fact characterizes the protective barrier "continuity" on specimen no. 2 .

The structure-phase composition of specimen no. 3 involves $45 \%$ of martensite, $0 \%$ of ferrite, and $45 \%$ of bainite. In this case, the formation of the protective layer on the surface is completed in $1 \mathrm{~h}$ of the test. During this time, oxygen freely migrates to the specimen surface, free $\mathrm{Fe}^{2+}$ ions are absent in zone $\boldsymbol{I}$, whereas their amount in zone $\boldsymbol{I I}$ increases (Fig. 6c, 7c). Later on, in the period from 1 to $3 \mathrm{~h}$, the amount of $\mathrm{Fe}^{3+}$ in zone II starts to grow due to $\mathrm{Fe}^{2+}$ oxidation, but the decrease in $\mathrm{Fe}^{2+}$ amount occurs more slowly than the increase in $\mathrm{Fe}^{3+}$ amount. This fact suggests that $\mathrm{Fe}^{2+}$ is continuously delivered from the specimen surface to the solution from the layer of corrosion products or through it. Hence it is obvious that the "protective effect" of the layer on specimen no. 3 is less pronounced than that on specimens no. 2 and no. 3 .

Thus, it has been shown using the proposed technique that the presence of ferrite and martensite structures affects the corrosion resistance of heat-affected corrosion areas of welding seams in $30 \% \mathrm{NaCl}$ solution. On the other hand, the structure of the heat-affected zone that mostly contains bainite demonstrates a tendency to enhance the "protective effect" due to formation of a stronger layer of corrosion products of the surface of the main metal (Figure 5, 6b, 7b).

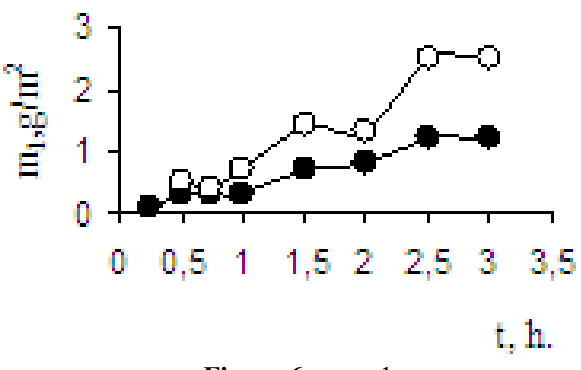

Figure 6a . no. 1

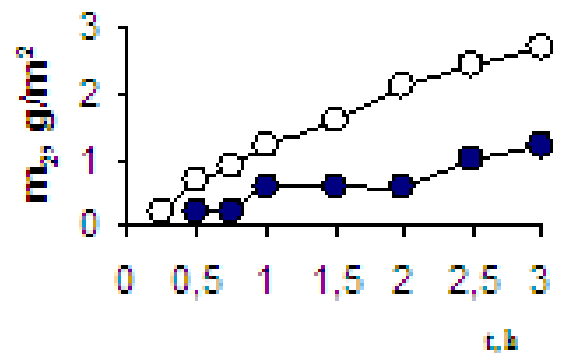

Figure 6b. no 2 


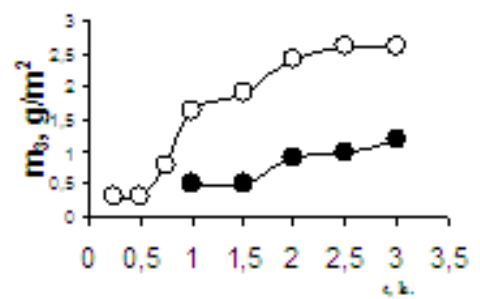

Figure 6c. no. 3 .

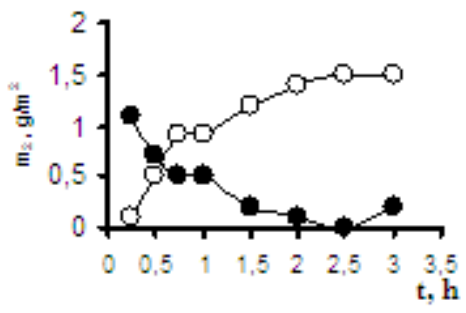

Figure 7a. no. 1

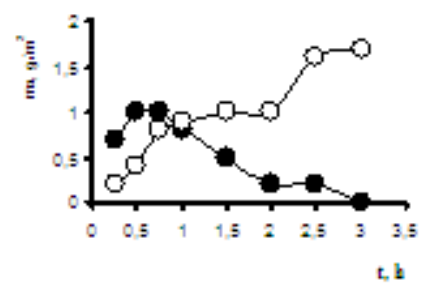

Figure 7a. no. 2

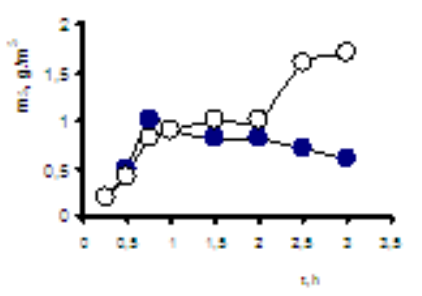

Figure 7a. no. 3

\section{Conclusions and prospects}

As our studies show, estimation of the corrosion kinetics of metals by CDCP allows one to perform a high-accuracy, selective and quantitative analysis of the corrosion behavior of steel at varying surface states (stress ageing, structure-phase and stressed states, various surface structure, etc. ) and to estimate the protection efficiency and service time of anticorrosion coatings, inhibitors and other protection systems in various corrosive environments. Furthermore, we believe that further development of CDCP shows promise in the following areas:

- development of new anticorrosion materials;

- study of the corrosion kinetics of multiphase alloys, etc.

\section{Acknowledgements}

The authors thank Dr. S.Veselyi for help in preparing the text of the article and valuable comments.

\section{REFERENCES}

[1] Kuzmak A.E, Agasyan P.K, Kozheurov A.V. Zashch. Met., 1989, vol. 25, no. 2, pp. 179-190 (in Russian).

[2] Karyakina M.I. and Kouzmak A.E. Progress in organic coatings.1990, 325- 388.

[3] Nowicki V.S., Pischik L.M. Corrosion monitoring of process equipment. , "Naukova Dumka", p.171, 2001 (in Russian).

[4] Zoua Y., Wanga J. and Zhenga Y.Y. Corros.sci. 53(2011), pp.208-216

[5] Gonzalez J.A., Miranda J.M., Otero E. and Felu S., Corros.Sci. 49 (2007).pp.1711- 1124.

[6] García K.E., Morales A.L., Barrero C.A. and Greneche J.M, Corros. Sci. 48 (2006), pp. 2813-2830.

[7] Feliu S. J.C., Galván, S. Feliu Jr., Bastidas J.M, Simancas J., Morcillo M. and Almeida E.M., Corros. Sci. 35 (1993), pp. 1351-1358.

[8] Walter G.W.Corr.sci.26.(1986), pp.681-703.

[9] Meszaros H., Janaszik F., Lenglyl B. Farbe und Lack. 1982. B.88. №10.S.813.

[10] Kuzmak A.E. and Kozheurov A.V. Coulometric Estimation of Corrosion Rate of Carbon Steel. Protection of metals, 40, No. 3, pp. 289-293 (2004).

[11] Agasyan PK, TK Hamrakulov. The coulometric method of analysis. Moscow, "Chemistry", 167 pp. 1984.

[12] Shirokova V.I. Zh. Anal. Khim., 2003, vol. 58, no. 9, pp. 928-931 (in Russian).

[13] Plembek J. A. Electrochemical chemistry. Basic Principles and Applications, A Wiley-Interscience Publicatioon. John Wiley@ Sons. New York, Chichester, Brisbane, Toronto, Singapore. 1985, 496 pp.

[14] Demkin A.M., Zh. Anal. Khim., 2000. v.55, no.2, 195-200 (in Russian).

[15] Demkin A.M., Zh. Anal. Khim., 2006. v.61, no.2, 164-169 (in Russian).

[16] Demkin A.M., J. Analyt. Chemistry. 2000. v.55, no. 2, 195-200.

[17] Demkin A.M. , J. Analyt. Chemistry 2006. v.61, no. 2, 164-169.

[18] Equipment and methods for physicochemical measurements / Ed. V.S.Tikhonov, Kiev, 1984, 110 pp.

[19] Konorov P.P., Yafyasov A.M. Physics of the surface of semiconductor electrodes. - St. Petersburg.:St. Petersburg University Press, 2003. 532 pp (in Russian).

[20] Tamm I.E. On the possibility of associated states of electrons on the surface of a crystal. / / Zh. Exper. and theor. Physics, 1933. vol. 3. pp. 34-43 (in Russian). 
[21] Shocley W.On the surface state associated with periodic potential.// Phys., no.1. P.319-326.

[22] Pharizeou P. Subsurface states in one dimensional crystals // Physica. 1960. Vol.26, no. 12. P.1192-1200.

[23] Wolkenstein F.F. Electronic Theory of catalysis on semiconductors. Fizmatgiz, 1960.187 pp. (in Russian) 